\title{
Modal testing and modelling the dynamic characteristics of a plate with bolted joints
}

\author{
A.R. Bahari' ${ }^{1}$, M.A. Yunus ${ }^{*}$, M.N. Abdul Rani ${ }^{1}$ and A.A. Prakasam² \\ 1 Structural Dynamics Analysis \& Validation (SDAV), Faculty of Mechanical Engineering, Universiti Teknologi MARA (UiTM), 40450 Shah Alam, \\ Selangor, Malaysia \\ Phone: +60355436202; Fax: +60355435160 \\ 2 MSC Software Corporation India Pvt. Ltd., Bangalore, Karnataka, India 560043
}

\begin{abstract}
Modelling the dynamic characteristics of the bolted joints in a complex assembled structure with a high accuracy is very challenging due to the assumptions and uncertainties in the input data of the FE model. In this paper, the identification of the dynamic characteristics of the bolted joints structure using the CBUSH element connector is proposed. Modal testing and normal modes analysis are conducted on a thin plate assembled structure with bolted joints. In the simulation work, the CBUSH element connector is employed and the stiffness coefficient for six degrees of freedom is computed based on four flexibility formulae. The predicted natural frequencies and their corresponding mode shapes are compared against the results of the experimental work. A good agreement of the FE model is achieved by using the coefficient of stiffness as represented in the Swift flexibility formula. The study justifies that the dynamic characteristics of the bolt joints could be accurately modelled by using the CBUSH element connector. The obtained findings provided an alternative approach to modelling the dynamic characteristics of a thin plate assembled structure with bolted joints.
\end{abstract}

\section{ARTICLE HISTORY}

Received: $15^{\text {th }}$ Feb. 2021

Revised: 20th Aug. 2021

Accepted: $04^{\text {th }}$ Oct. 2021

\section{KEYWORDS}

Dynamic characteristics; bolted joint;

normal modes;

stiffness;

element connector.

\section{INTRODUCTION}

Mechanical joints play an important role in engineering components and structural systems. Various mechanical fastening methods comprising bolts, welds, rivets and pins [1] are used to transfer loads in the operation conditions from one structural element to another to ensure structural integrity, component alignment and sealing [2,3]. Bolted joints are widely used in mechanical engineering, civil and building fields, aerospace engineering and complex space structures $[4,5]$. For instance, bolted joints are preferred in the steel construction field as an alternative to the welded connections due to its flexibility of reassembling and disassembling [6]. In advanced composite structure applications, the reliability and strength property of the bolted connections in joining main structural parts have made it a more preferable type of fastening mechanism compared to the adhesive bonded joints [7, 8].

The structural behaviour of the complete assembly of the systems and structures, especially under random dynamic loadings over a period of time, depends critically on the existing condition at the joint connections [9]. Additional energy dissipation is established by the bolted joints which give rise to the overall stiffness that instantaneously affects the damping and natural frequencies of the structure. Thus, the dynamic characteristics of such bolted structural elements like natural frequencies and mode shapes have to be reliably understood in order to circumvent the resonance risk which might precipitate accidents and catastrophic malfunction such as deformation, fracture and damage during service operation $[10,11]$.

The numerical simulation in modelling the dynamic characteristics of the bolted joints prior to obtaining an accurate FE model is challenging and complex in nature $[12,13]$. In particular, the bolted joints involve several different sources of uncertainties, such as contact forces which are not ideally plane due to manufacturing tolerances of contact surfaces and the non-uniform distribution of initial forces in the lateral load existence [14]. As a result, some improvements in establishing a predictive model of structures with joints and interfaces have been scrutinised recently. The dynamic characteristics of a structure are significantly affected by mass, stiffness and damping effects of the bolted joints [15, 16]. However, modelling the stiffness and damping effects is difficult in comparison to the mass effect due to its main relationship with the surface property of contact interfaces, the pre-loadings and clamping force caused by assembling the structure $[17,18,19]$.

Application has to be separately investigated on a case-by-case basis as a general approach in modelling the dynamic characteristics of bolted joints has never existed [20,21,22]. There are several modelling approaches that can be adopted such as the solid bolt model, the coupled bolt model and the spider bolt model [12, 23, 24]. Lee [25] modelled the joints represented by having flexible connections with linear stiffness and damping, while Rutman et al. [26] and Omar et al. [27] modelled the bolted joint of plates by using a combination of different types of connector elements. This paper proposes the modelling of the dynamic characteristics of bolted joints based on vibrational natural frequencies and mode shapes, where four flexibility formulae are used to compute the translational and rotational stiffness of the bolted joints through the implementation of the CBUSH element connector. 


\section{EXPERIMENTAL MODAL ANALYSIS}

In order to analyse the dynamic characteristics of the bolted joint, two identical geometric plates with a $90^{\circ}$ bend at the ends were assembled using bolts as shown in Figure 1. The structure is made from cold rolled mild steel with a thickness of $1.43 \mathrm{~mm}$. Table 1 lists the material properties of the plate and their corresponding values.

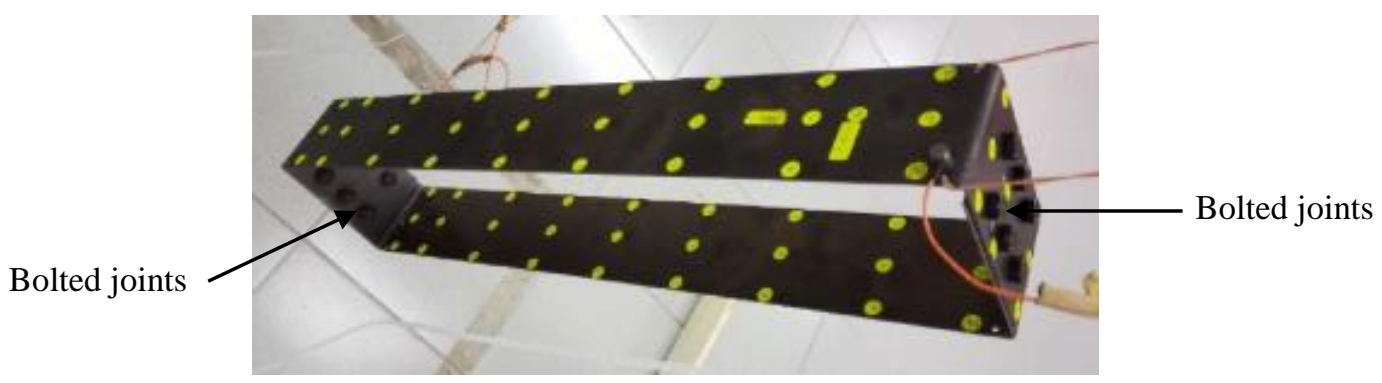

Figure 1. Thin plate assembled structure with bolted joints

Table 1. Material properties of the structure

\begin{tabular}{lcc}
\hline \multicolumn{1}{c}{ Parameter } & Value & Unit \\
\hline Young's Modulus & 203000 & $\mathrm{MPa}$ \\
Poisson's Ratio & 0.3 & \\
Density & 7980 & $\mathrm{~kg} / \mathrm{m}^{3}$ \\
Thickness & 1.43 & $\mathrm{~mm}$ \\
\hline
\end{tabular}

The structure comprises twelve bolts and nuts which are used on each side of the plate and the assembled structure are considered to be a perfectly symmetrical bolt lap joint connection and the class 8.8 of M6 high-strength steel hex head type is used to assemble the component to form the assembled structure. The bolt preload torque applied is equal to 5.0 N.m and the specifications are as listed in Table 2.

Table 2. Bolt properties

\begin{tabular}{lcc}
\hline Parameter & Value & Unit \\
\hline Material & High tensile steel & \\
Class & 8.8 & \\
Diameter & 6.0 & $\mathrm{~mm}$ \\
Length & 10.0 & $\mathrm{~mm}$ \\
\hline
\end{tabular}

\section{Experimental Set Up}

This experimental work was set up to measure vibrational acceleration at selected points. The implementation of the experimental setup shown in Figure 2(a) and 2(b) were necessary to determine the dynamic characteristics that corresponded with the bolted joints. Soft springs were used to vertically suspend the structure to form free-free boundary conditions. This setup was chosen to minimise the effects of gravity when obtaining accurate dynamic characteristics. An impact hammer with a plastic tip was instrumented with a force transducer at the tip location in order to measure the magnitude of force during impact excitation. The location for the impact excitation in Figure 2(a) was chosen to ensure that all the flexible body modes were well-excited. 


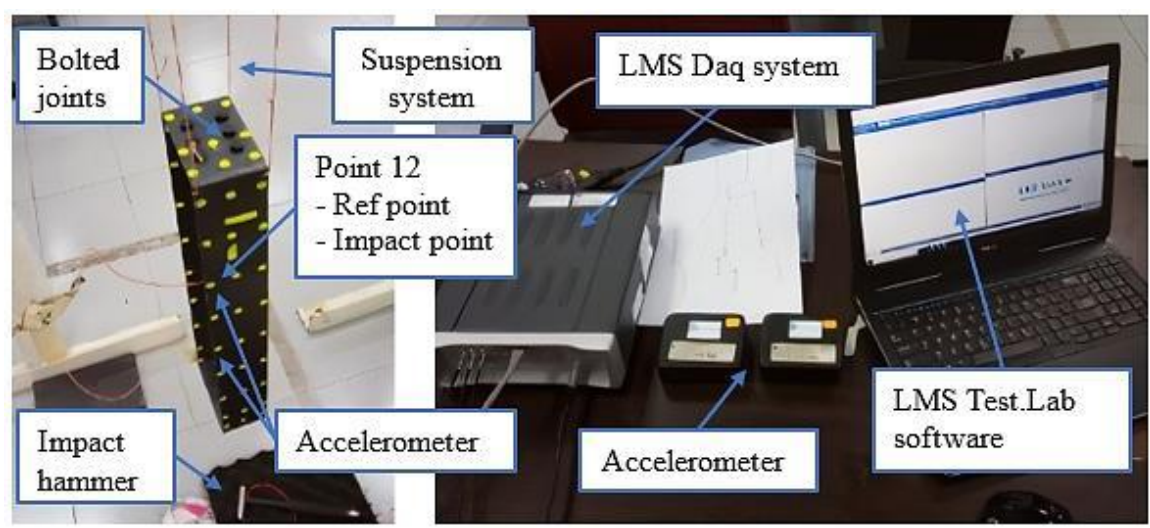

(a)

Figure 2. Setting up an experimental modal analysis: (a) suspension system to simulate free-free boundary conditions and (b) testing equipment

The tested bolted structure was instrumented with three accelerometers which were mounted to obtain the dynamic response after being lightly impacted. It is noted that one accelerometer was used for reference, at a specific location point of 12, while two other accelerometers were used for roving. Each accelerometer was 2 grams in weight, which contributed to the total percentage of $0.02 \%$ for the ratio of mass of accelerometers to mass of structure. Wax was used to mount the accelerometer in order to get a good contact between accelerometer and structure. With a near perfect set up, there was therefore no mass loading issue.

\section{Experimental Procedure}

Modal testing by impact hammer excitation was performed at an appropriate specific location point of 12 in order to verify that both of the bending and torsional modes were well excited. This impact point was constantly fixed throughout the measurement. The acceleration responses were measured at all points resulting in a total number of 36 points altogether. Roving accelerometers were utilised to determine the mode shapes.

On the vertical surface of the structure, the acceleration response was in the $Z$ axis direction, while at the side of the structure which was the location of the bolted joint connection, the acceleration responses were measured in the $X$ axis direction (refer Figure 2). The mode shapes of the bolted structure were acquired by summing up all 36 measured acceleration responses into a single frequency response function. For each measurement point, the dynamic response in terms of frequency response function was recorded by five measurement averages. The frequency range was 0 to $256 \mathrm{~Hz}$ and the frequency resolution was at $0.5 \mathrm{~Hz}$. In this study, all the dynamic characteristics of the bolted structure were determined including their natural frequencies and mode shapes.

\section{FINITE ELEMENT MODELLING AND NORMAL MODE ANALYSIS}

A numerical simulation analysis was carried out in order to predict the dynamic characteristics of the bolted structure. The structure was modelled with free-free boundary conditions. Figure 3 shows a combination of 19218 mixed types of triangle and quadrilateral elements and 19973 nodes were assigned for the meshing of the structure at a size of $2 \mathrm{~mm}$. Multi-point constraints of rigid body elements (RBE2) were used to represent the bolts' head and nut as shown in Figure 4. The bolts' shank was represented by CBUSH element connector.

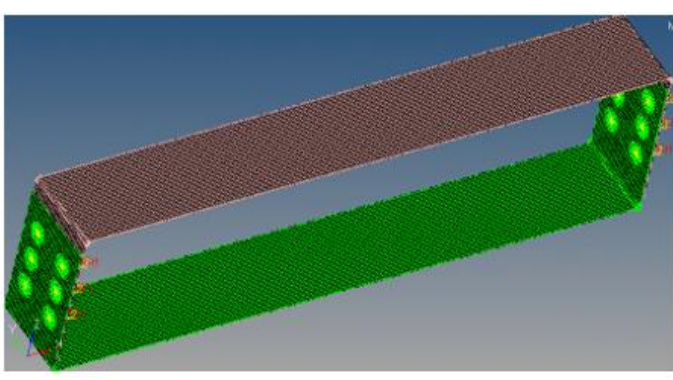

(a)

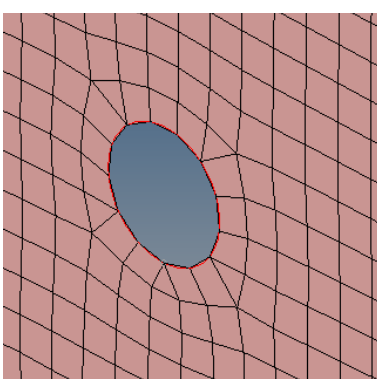

(b)

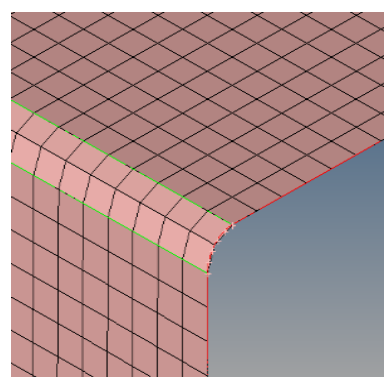

Figure 3. FE model: (a) thin plate assembled structure with bolted joints and (b) meshing 


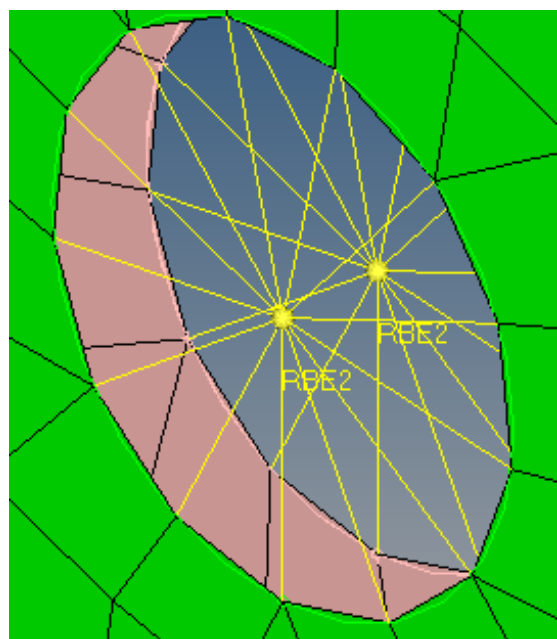

(a)

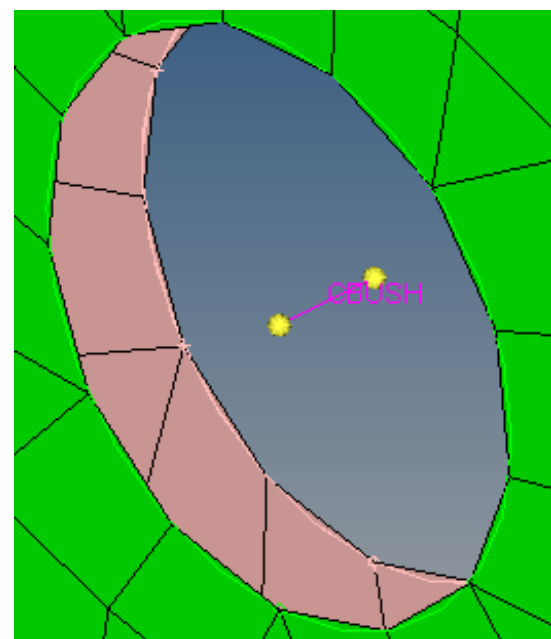

(b)

Figure 4. (a) Multi-point constraints of rigid body elements (RBE2) and (b) CBUSH element connector

A single degree of freedom mass-spring-damper system (Figure 5) was employed. The mathematical model used for the dynamic characteristics of the system is the second order differential equation of motion which is represented by Eq. (1), where $M, C$ and $K$ are mass matrix, damping matrix and stiffness matrix respectively. Meanwhile, $x \ddot{*} x$ and $x$ are the vectors of acceleration, velocity and displacement. $F(t)$ is the vector of external force.

$$
M \ddot{x}(t)+C \dot{x}(t)+K x(t)=F(t)
$$

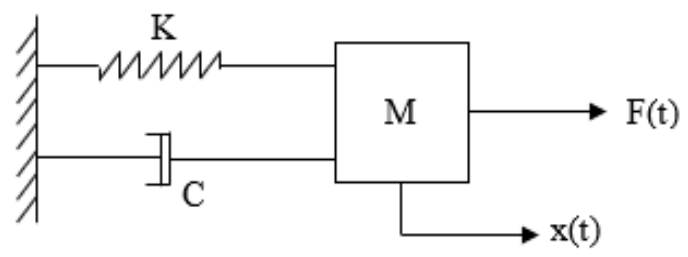

Figure 5. Mass-spring-damper system

For a lightly damped condition, the modal decomposition considered the undamped system. For an undamped free vibration analysis, the damping and applied external forces were ignored and the equation of motion [28] is represented by Eq. (2). The eigenvalue problem is Eq. (3).

$$
\begin{aligned}
& M \ddot{x}(t)+K x(t)=0 \\
& -\omega_{i}^{2} M \emptyset_{i}+K \emptyset_{i}=0
\end{aligned}
$$

where $\emptyset_{i}$ and $\omega_{i}$ are the mode shape and natural frequency. This equation can be written in the form of an eigenvector problem [29] by using Eq. (4) where $\emptyset_{i}$ is an eigenvector and $\omega_{i}{ }^{2}$ is the corresponding eigenvalue of $M^{-1} K$.

$$
M^{-1} K \emptyset_{i}=\omega_{i}^{2} \emptyset_{i}
$$

The Lanczos method was applied in the modal analysis in order to compute the free vibration modes derived from the magnitude and distribution of the structural stiffness, damping and mass [30, 31]. The algorithm is based on the calculation of a symmetric matrix eigenvalue problem. All the structures displayed non-identical mode shapes which corresponded to the natural frequencies at a local and a global level.

The dynamic characteristics of the bolted joint between the two plates at both sides of the structure were modelled by implementing the CBUSH element connector consisting of six parameter stiffness; three translational and three rotational stiffness in the three dimensions of $x, y$ and $z$ direction. Translational stiffness refers to the axial and shear stiffness defined in the PBUSH entry. For the CBUSH element, axial stiffness, $K_{l}$ is calculated by using Eq. (5).

$$
K_{1}=\frac{E \times S}{L}
$$

where $E$ is Young's modulus of the bolt, $L$ is length of the bolt and $S$ is area of the section of the bolt. $K_{2}$ and $K_{3}$ refer to the shear stiffness of the CBUSH element which is calculated in Eq. (6). 


$$
K_{2}=K_{3}=\frac{1}{C}
$$

where $C$ is the bolt flexibility. Rotational stiffness around the axis of the bolt, $K_{4}$ is fixed at 100 N.m. Rotational stiffness at other directions is calculated by using Eq. (7).

$$
K_{5}=K_{6}=\frac{1}{\varepsilon} \times\left(\operatorname{Max}\left(K_{2}, K_{3}\right) \times \frac{\left(L_{C B U S H}\right)^{2}}{4}\right)
$$

where $1 / \varepsilon$ is fixed at $100 . \operatorname{Max}\left(K_{2}, K_{3}\right)$ is the maximum value taken from the calculation of $K_{2}$ or $K_{3}$ while $L_{C B U S H}$ is the length of the CBUSH element. Flexibility contributes to the shear stiffness of $K_{2}$ and $K_{3}$. Four different flexibility formulae were used for the calculation of CBUSH stiffness in this study, namely Huth, Tate \& Rosenfeld, Grumman and Swift. The equation of flexibility is shown from Eqs. (8) to (11). The flexibility value was employed as an input parameter for the calculation of $K_{2}$ and $K_{3}$ in the CBUSH element representing shear and rotational stiffness of the bolt joint. Table 3 shows the nomenclatures of the formula.

Huth [32, 33]:

$$
C=\left(\frac{t_{1}+t_{2}}{2 d}\right)^{a} \cdot \frac{b}{n}\left(\frac{1}{t_{1} E_{1}}+\frac{1}{n t_{2} E_{2}}+\frac{1}{2 t_{1} E_{3}}+\frac{1}{2 n t_{2} E_{3}}\right)
$$

Tate \& Rosenfeld [34, 35]:

$$
\begin{gathered}
C=\frac{1}{t_{1} E_{1}}+\frac{1}{t_{2} E_{2}}+\frac{1}{t_{1} E_{3}}+\frac{1}{t_{2} E_{3}}+\frac{32\left(t_{1}+t_{2}\right)\left(1+v_{3}\right)}{9 E_{3} \pi d^{2}} \\
+\frac{8\left(t_{1}{ }^{3}+5 t_{1}{ }^{2} t_{2}+5 t_{1} t_{2}{ }^{2}+t_{2}{ }^{3}\right)}{5 E_{3} \pi d^{4}}
\end{gathered}
$$

Grumman $[33,35]$ :

$$
C=\frac{\left(t_{1}+t_{2}\right)^{2}}{E_{3} d^{3}}+3.7\left(\frac{1}{t_{1} E_{1}}+\frac{1}{t_{2} E_{2}}\right)
$$

Swift [36]:

$$
C=\frac{1}{E_{1} d}\left(A+B d\left(\frac{1}{t_{1}}+\frac{1}{t_{2}}\right)\right)
$$

Table 3. Nomenclatures of bolt flexibility equation

\begin{tabular}{ll}
\hline Variable & Description \\
\hline$E_{1}$ & Young's modulus of plate 1 $(\mathrm{MPa})$ \\
$\mathrm{E}_{2}$ & Young's modulus of plate 2 $(\mathrm{MPa})$ \\
$\mathrm{E}_{3}$ & Young's modulus of bolt $(\mathrm{MPa})$ \\
$\mathrm{v}_{3}$ & Poisson's ratio of bolt \\
$\mathrm{t}_{1}$ & Thickness of plate $1(\mathrm{~mm})$ \\
$\mathrm{t}_{2}$ & Thickness of plate $2(\mathrm{~mm})$ \\
$\mathrm{a}$ & $2 / 3$ (bolted metallic) \\
$\mathrm{b}$ & 3 (bolted metallic) \\
$\mathrm{A}$ & 1.67 (steel bolt) \\
$\mathrm{B}$ & $0.86($ steel bolt) \\
$\mathrm{d}$ & Diameter of the bolt $(\mathrm{mm})$ \\
$\mathrm{n}$ & $1($ single shear $)$ \\
\hline
\end{tabular}


The values of flexibility, shear stiffness and rotational stiffness of the bolt were calculated and the results tabulated in Table 4. For the numerical work, the normal mode analysis was carried out on the dynamic characteristics of the bolted structure with a frequency of interest of below $256 \mathrm{~Hz}$. The natural frequencies and mode shapes were extracted from the modal testing and normal mode analysis. Comparison analyses were performed in order to evaluate the practicality of each flexibility formula to accurately model the dynamic characteristics of the bolted joints.

Table 4. Flexibility and stiffness values representing bolt joint connection with different flexibility formulae

\begin{tabular}{llll}
\hline \multirow{2}{*}{ Flexibility Formula } & $\begin{array}{l}\text { Flexibility, } \\
C(\mathrm{~mm} / \mathrm{N})\end{array}$ & $\begin{array}{l}\text { Shear Stiffness, } \\
K_{2} \text { and } K_{3}(\mathrm{~N} / \mathrm{mm})\end{array}$ & $\begin{array}{l}\text { Rotational Stiffness, } \\
K_{5} \text { and } K_{6}(\mathrm{~N} / \mathrm{mm})\end{array}$ \\
\hline Huth & $1.1754 \mathrm{E}-05$ & $8.5075 \mathrm{E}+04$ & $4.3493 \mathrm{E}+06$ \\
Swift & $7.2676 \mathrm{E}-06$ & $1.3760 \mathrm{E}+05$ & $7.0343 \mathrm{E}+06$ \\
Grumman & $2.5572 \mathrm{E}-05$ & $3.9105 \mathrm{E}+04$ & $1.9992 \mathrm{E}+06$ \\
Tate \& Rosenfeld & $1.4145 \mathrm{E}-05$ & $7.0697 \mathrm{E}+04$ & $3.6142 \mathrm{E}+06$ \\
\hline
\end{tabular}

\section{IDENTIFICATION OF THE MODELLING OF DYNAMIC CHARACTERISTICS}

As stated earlier, modelling the dynamic characteristics of the thin plate assembled structure with bolted joints was carried out based on the natural frequencies and mode shapes that were measured during the modal testing and calculated using the normal modes FE analysis. Tables 5 and 6 present the experimental and numerical vibrational natural frequencies that corresponded respectively to each mode. The numerical results were obtained by utilising four different flexibility formulae for the bolted joint connections. Nine flexible vibrational modes were available in the frequency range of between $0 \mathrm{~Hz}$ and $256 \mathrm{~Hz}$. The natural frequencies were compared between the EMA and FE modelling, while the detailed results of the discrepancies were listed in these tables for the evaluation of the dynamic characteristics modelling.

The comparison of the results which adopted the Swift flexibility formula with the lowest total error of 11.32 per cent shows that the bolted joints were well modelled. The utilisation of the other three flexibility formulae; Huth, Tate \& Rosenfeld and Grumman produced less accuracy in modelling the dynamic characteristics in comparison to the Swift flexibility formula. In detail, a significant improvement at mode 4 with the lowest discrepancy of 1.76 per cent was obtained. Based on Figure 6 which explains the mode shape for each vibration mode, mode 4 was identified as the first torsion mode. The natural frequency of $65.25 \mathrm{~Hz}$ was closer to the natural frequency obtained from the modal testing which was $66.42 \mathrm{~Hz}$. This corresponded to the higher value of shear stiffness $K_{2}$ and $K_{3}$ calculated by the Swift flexibility formula as listed in Table 6. On the other hand, utilising the Grumman flexibility formula contributed to the highest total error of 14.51 percent.

In general, the natural frequencies obtained from the numerical analysis of flexural modes 3,6 and 9 slightly exceeded that of the experimental values, while flexural modes 4,5 and 8 were slightly lower. The obtained values from the numerical analysis were similar to the experimental results for flexural modes 1, 2 and 7, but with a higher degree of accuracy. In terms of the error for each particular mode, mode 3 which corresponded to the third bending elastic mode had the highest error of about 3.50 per cent.

Table 5. Comparison of EMA and FE results using Huth and Tate \& Rosenfeld flexibility formulae

\begin{tabular}{lllllc}
\hline & I & II & III & \multicolumn{1}{c}{ IV } & $\begin{array}{l}\text { V } \\
\text { Mode }\end{array}$ \\
\hline 1 & $\begin{array}{l}\text { Experiment } \\
(\mathrm{Hz})\end{array}$ & $\begin{array}{l}\text { Huth } \\
(\mathrm{Hz})\end{array}$ & $\begin{array}{l}\text { Error }(\%) \\
(\mathrm{I}-\mathrm{II})\end{array}$ & $\begin{array}{l}\text { Tate } \text { Rosenfeld } \\
(\mathrm{Hz})\end{array}$ \\
\hline 2 & 30.54 & 30.28 & 0.85 & 30.24 & 0.98 \\
3 & 39.62 & 39.42 & 0.50 & 39.42 & 0.50 \\
4 & 46.51 & 48.13 & 3.48 & 48.13 & 3.48 \\
5 & 66.42 & 64.87 & 2.33 & 64.72 & 2.56 \\
6 & 86.02 & 85.59 & 0.50 & 85.50 & 0.6 \\
7 & 117.94 & 120.30 & 2.00 & 120.30 & 2.00 \\
8 & 169.66 & 169.63 & 0.02 & 169.45 & 0.12 \\
9 & 179.31 & 178.98 & 0.18 & 178.97 & 0.17 \\
\hline
\end{tabular}


Table 6. Comparison of EMA and FE results using Grumman and Swift flexibility formulae

\begin{tabular}{llllll}
\hline & I & II & III & IV & V \\
\hline Mode & $\begin{array}{l}\text { Experiment } \\
(\mathrm{Hz})\end{array}$ & $\begin{array}{l}\text { Grumman } \\
(\mathrm{Hz})\end{array}$ & $\begin{array}{l}\text { Error }(\%) \\
(\mathrm{I}-\mathrm{II})\end{array}$ & $\begin{array}{l}\text { Swift } \\
(\mathrm{Hz})\end{array}$ & $\begin{array}{l}\text { Error }(\%) \\
(\mathrm{I}-\mathrm{IV})\end{array}$ \\
\hline 1 & 30.54 & 30.11 & 1.41 & 30.37 & 0.56 \\
2 & 39.62 & 39.41 & 0.53 & 39.42 & 0.50 \\
3 & 46.51 & 48.12 & 3.46 & 48.14 & 3.50 \\
4 & 66.42 & 64.24 & 3.28 & 65.25 & 1.76 \\
5 & 86.02 & 85.23 & 0.92 & 85.80 & 0.26 \\
6 & 117.94 & 120.27 & 1.98 & 120.33 & 2.03 \\
7 & 169.66 & 168.88 & 0.46 & 170.06 & 0.24 \\
8 & 179.31 & 178.93 & 0.21 & 179.01 & 0.17 \\
9 & 200.38 & 204.91 & 2.26 & 204.98 & 2.30 \\
\hline
\end{tabular}

Table 7 shows the mode shapes corresponding to each natural frequency of the experimental modal and normal modes analyses which represent the modelling of the dynamic characteristics of the thin plate bolted structure using the Swift flexibility formula. From this table, it is observed that six flexural modes; 1, 2, 3, 5, 6 and 9 were elastic bending modes in the $x$ and $z$ direction. Also, three flexural modes 4, 7 and 8 were elastic torsional modes in the $y$ and $z$ direction.

A comparison on the accuracy of the mode shapes between the EMA and FE models had also been performed by computing the modal assurance criterion (MAC) value which was calculated by using Eq. (12) where experimental ( $\left.\phi_{m}\right)$ and FE $\left(\phi_{a}\right)$ mode shapes were in the matrix form, respectively. MAC was used to quantify the correlation level of mode shapes between the FE and experimental models [37]. As seen in Table 7, the MAC value for each vibrational mode was above 0.88. Thus, a good correlation between the experimental and FE models for both bending and torsional mode shapes was revealed.

$$
\operatorname{MAC}=\left(\varphi_{\mathrm{m}} \varphi_{\mathrm{a}}\right)=\frac{\left|\varphi_{\mathrm{m}}{ }^{\mathrm{T}} \varphi_{\mathrm{a}}\right|^{2}}{\left(\varphi_{\mathrm{a}}^{\mathrm{T}} \varphi_{\mathrm{a}}\right)\left(\varphi_{\mathrm{m}}{ }^{\mathrm{T}} \varphi_{\mathrm{m}}\right)}
$$

Table 7. Mode shapes of the predicted and measured dynamic characteristics of the bolted structure

\begin{tabular}{llll}
\hline Mode & Finite Element Analysis & MAC Value \\
\hline 1 & $30.37 \mathrm{~Hz}$ & 0.98 \\
2 & &
\end{tabular}


Table 7. Mode shapes of the predicted and measured dynamic characteristics of the bolted structure (cont.)

\begin{tabular}{c|c} 
Mode & Finite Element Analysis \\
\hline 3 &
\end{tabular}

$48.14 \mathrm{~Hz}$

4

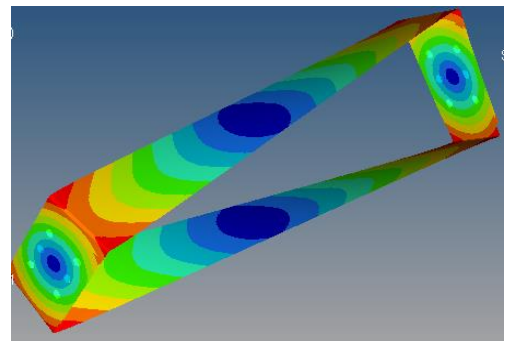

$65.25 \mathrm{~Hz}$

5

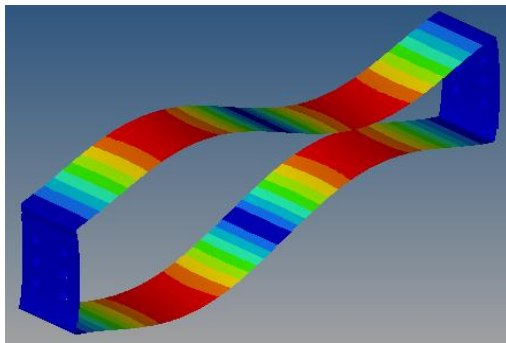

$85.80 \mathrm{~Hz}$

6

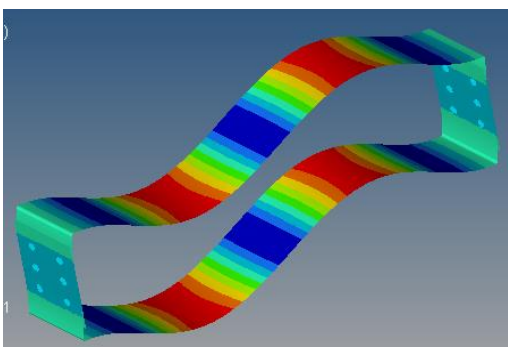

$120.33 \mathrm{~Hz}$

7

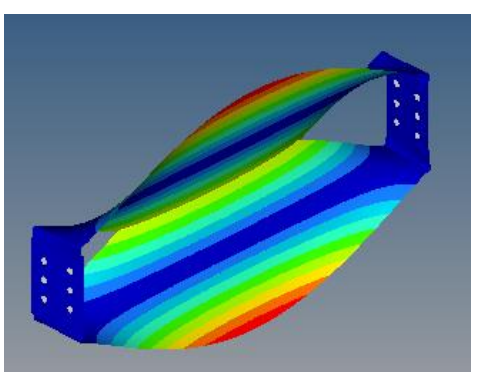

$170.06 \mathrm{~Hz}$

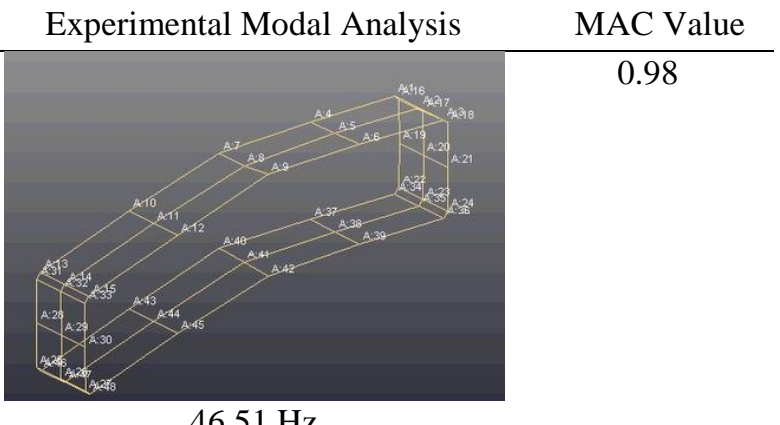

0.95

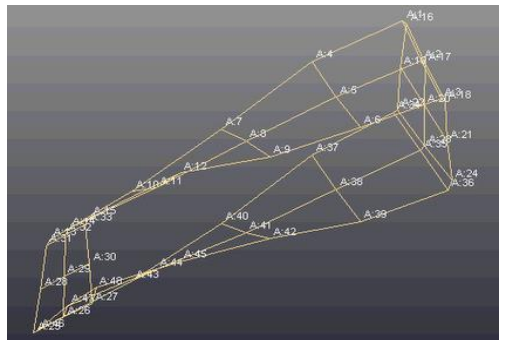

$66.42 \mathrm{~Hz}$

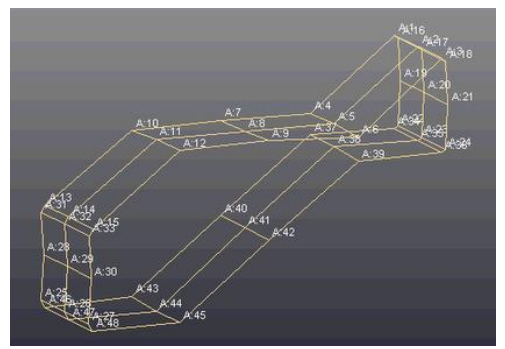

$86.02 \mathrm{~Hz}$

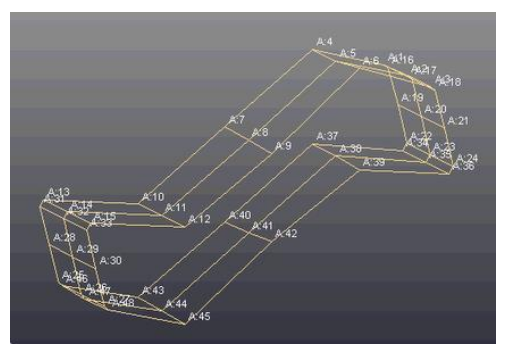

$117.94 \mathrm{~Hz}$

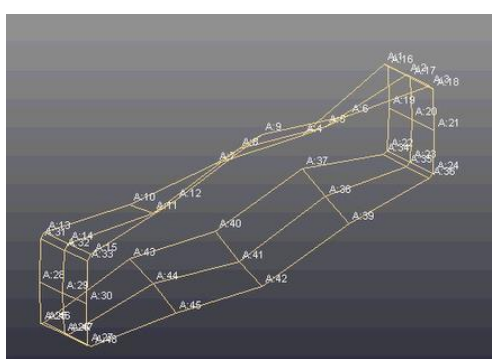

$169.66 \mathrm{~Hz}$
0.96

0.92

0.88 
Table 7. Mode shapes of the predicted and measured dynamic characteristics of the bolted structure (cont.)

\begin{tabular}{c|ccc}
\hline Mode & Finite Element Analysis & Experimental Modal Analysis & MAC Value \\
\hline 8 & & 0.89 \\
$179.01 \mathrm{~Hz}$ & $179.31 \mathrm{~Hz}$
\end{tabular}

9

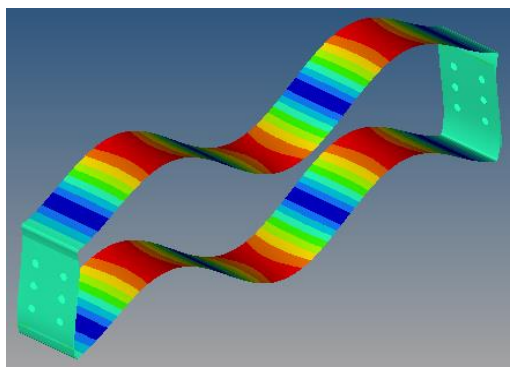

$204.98 \mathrm{~Hz}$

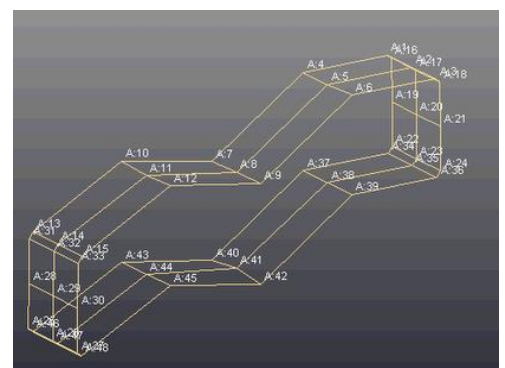

$200.38 \mathrm{~Hz}$
0.96

\section{CONCLUSIONS}

The dynamic characteristics of a thin plate assembled structure with bolted joints were investigated experimentally and numerically. Nine flexible bending and torsional modes in the frequency range of 0 to $256 \mathrm{~Hz}$ were obtained from the modal testing under free-free boundary conditions. In the preparation of the FE model for the normal modes analysis, four flexibility formulae were used to calculate the stiffness of the bolted joints namely; Huth, Swift, Grumman and Tate \& Rosenfeld. The CBUSH element connector was utilised to model the translational and rotational stiffness of the bolted joints at six degrees of freedom. It could be seen that the discrepancy of the natural frequencies of the bolted joints that were modelled by the Swift flexibility formula produced the lowest total error of 11.32 percent in comparison to Huth, Grumman and Tate \& Rosenfeld. Furthermore, this finding was also supported by good mode shapes of above 0.88 MAC value.

\section{ACKNOWLEDGMENTS}

The research work herein was supported by the Malaysian Ministry of Higher Education (MOHE) under Fundamental Research Grant Scheme, Grant No. 600-IRMI/FRGS 5/3/ (465/2019). This support is gratefully acknowledged.

\section{REFERENCES}

[1] Y. Zuo, Z. Cao, G. Zheng, and Q. Zhang, "Damage behavior investigation of CFRP/Ti bolted joint during interference fit bolt dynamic installation progress," Eng. Fail. Anal., vol. 111, p. 104454, 2020.

[2] Y. Kwak, S. M. Park, and J. Park, "Dynamic properties of bolted joints in laminated composites evaluated using flexural wave propagation," Mech. Res. Commun., vol. 92, pp. 37-42, 2018.

[3] J. Liu et al., "Dynamic behaviour of a bolted joint subjected to torsional excitation," Tribol. Int., vol. 140, p. $105877,2019$.

[4] J. Armand, L. Salles, C. W. Schwingshackl, D. Süß, and K. Willner, "On the effects of roughness on the nonlinear dynamics of a bolted joint: A multiscale analysis," Eur. J. Mech. / A Solids, vol. 70, pp. 44-57, 2018.

[5] Y. Li, Z. Liu, Y. Wang, L. Cai, and M. Zheng, "Experimental study on behavior of time-related preload relaxation for bolted joints subjected to vibration in different directions," Tribol. Int., vol. 142, p. 106005, 2020.

[6] D.-K. Kim and C.-H. Lee, "Experimental and analytical study of combined bolted-welded lap joints including high-strength steel," J. Constr. Steel Res., vol. 168, p. 105995, 2020.

[7] R. A. Ibrahim and C. L. Pettit, "Uncertainties and dynamic problems of bolted joints and other fasteners," J. Sound Vib., vol. 279, pp. 857-936, 2005.

[8] Z. Zhang, Y. Xiao, Y. Xie, and Z. Su, "Effects of contact between rough surfaces on the dynamic responses of bolted composite joints: multiscale modeling and numerical simulation," Compos. Struct., vol. 211, pp. 13-23, 2019.

[9] B. Qiu, X. Yang, Z. Zhou, and H. Lei, "Experimental study on fatigue performance of M30 high-strength bolts in bolted spherical joints of grid structures,” Eng. Struct., vol. 205, p. 110123, 2020. 
[10] S. Daouk, F. Louf, C. Cluzel, O. Dorival, L. Champaney, and S. Audebert, "Study of the dynamic behavior of a bolted joint under heavy loadings," J. Sound Vib., vol. 392, pp. 307-324, 2017.

[11] A. Rezaiefar and K. Galal, "Free vibration of thin rectangular steel plates with geometrically-nonlinear load-displacement behavior," Thin-Walled Struct., vol. 129, pp. 381-390, 2018.

[12] K. Zhang, G. Li, J. Gong, and F. Wan, "Modal analysis of bolted structure based on equivalent material of joint interface," Materials (Basel)., vol. 12, no. 18, p. 3004, 2019.

[13] W. Sun, T. Li, D. Yang, Q. Sun, and J. Huo, "Dynamic investigation of aeroengine high pressure rotor system considering assembly characteristics of bolted joints," Eng. Fail. Anal., vol. 112, p. 104510, 2020.

[14] A. Wettstein, T. Kretschmer, and S. Matthiesen, "Investigation of dynamic friction during impact tightening of bolted joints," Tribol. Int., vol. 146, p. 106251, 2020.

[15] K. He and W. D. Zhu, "Finite element modeling of structures with L-shaped beams and bolted joints," J. Vib. Acoust. Trans. ASME, vol. 133, no. 1, 2011.

[16] Ş. Tol and H. N. Özgüven, "Dynamic characterization of bolted joints using FRF decoupling and optimization," Mech. Syst. Signal Process., vol. 54-55, pp. 124-138, 2015.

[17] J. S. Tsai and Y. F. Chou, "The identification of dynamic characteristics of a single bolt joint," J. Sound Vib., vol. 125, pp. 487-502, 1988.

[18] M. Couchaux, M. Hjiaj, I. Ryan, and A. Bureau, "Effect of contact on the elastic behaviour of tensile bolted connections," J. Constr. Steel Res., vol. 133, pp. 459-474, 2017.

[19] P. Kulkarni and V. V. Kulkarni, "Effect of preload on natural frequency of bolted joint under impact loading," Int. J. Innov. Sci. Res. Technol., vol. 2, no. 6, pp. 185-188, 2017.

[20] M. A. Yunus, "Finite element modelling and updating of structure of sheet metal with bolted and welded joints," University of Liverpool, 2011.

[21] S. Bograd, P. Reuss, A. Schmidt, L. Gaul, and M. Mayer, "Modeling the dynamics of mechanical joints," Mech. Syst. Signal Process., vol. 25, pp. 2801-2826, 2011.

[22] P. Langer, K. Sepahvand, C. Guist, and S. Marburg, "Finite element modeling for structural dynamic analysis of bolted joints under uncertainty," Procedia Eng., vol. 199, pp. 954-959, 2017.

[23] J. Montgomery, "Methods for modeling bolts in the bolted joint," Int. ANSYS User's Conf., vol. 8, pp. 1-15, 2002.

[24] J. Kim, J.-C. Yoon, and B.-S. Kang, "Finite element analysis and modeling of structure with bolted joints," Appl. Math. Model., vol. 31, pp. 895-911, 2007.

[25] R. Y.-K. Lee, “Assessment of linear and non-linear joint effects on space truss booms,” Massachusetts Institute of Technology, Cambridge, 1985.

[26] A. Rutman, C. Boshers, L. Pearce, and J. Parady, "Fastener modeling for joining composite parts," in Americas Virtual Product Development Conference, 2009, pp. 1-28.

[27] R. Omar, M. N. Abdul Rani, M. A. Yunus, D. P. Starbuck, W. I. I. Wan Iskandar Mirza, and M. S. Mohd Zin, "Different flexibility formulae for finite element modelling and analysis of the dynamic behaviour of a structure with bolted joints," AIP Conf. Proc., vol. 2059, no. 1, p. 020004, 2019.

[28] A. R. Bahari, M. A. Yunus, M. N. Abdul Rani, W. I. I. Wan Iskandar Mirza, and A. R. Haizuan, "A comparative study of the vibrational effects on the boundary conditions of a slender beam," in AIP Conference Proceedings, 2019, vol. 2059, no. 020054, pp. 1-9.

[29] M. A. S. Aziz Shah, M. A. Yunus, M. N. Abdul Rani, M. S. Mohd Zin, and W. I. I. Wan Iskandar Mirza, "Finite element modelling of laser stitch welding joints for structural dynamic prediction," Int. J. Automot. Mech. Eng., vol. 16, no. 2, pp. 6556-6567, 2019.

[30] R. Kamgar and M. M. Saadatpour, "A simple mathematical model for free vibration analysis of combined system consisting of framed tube, shear core, belt truss and outrigger system with geometrical discontinuities," Appl. Math. Model., vol. 36, pp. 4918-4930, 2012.

[31] M. Isametova, B. Omarbekov, R. Nussipali, U. Angarbekov, and A. Isametov, "Computer simulation and investigation vibration parameters of a centrifugal submersible pump," J. Vibroengineering, vol. 22, no. 5, pp. 993-1005, 2020.

[32] H. Huth, "Influence of fastener flexibility on the prediction of load transfer and fatigue life for multiple-row joints," in Fatigue in Mechanically Fastened Composite and Metallic Joints, J. M. Potter, Ed. Philadelphia: ASTM STP 927, 1986, pp. $221-250$.

[33] S. Chandregowda and G. R. Chinnappa Reddy, "Evaluation of fastener stiffness modelling methods for aircraft structural joints," AIP Conf. Proc., vol. 1943, no. 020001, 2018.

[34] M. B. Tate and S. J. Rosenfeld, "Preliminary investigation of the loads carried by individual bolts in bolted joints," Washington, 1946.

[35] L. Jarfall, "Shear loaded fastener installations," Int. J. Veh. Des., vol. 7, pp. 337-380, 1986.

[36] İ. Uysal, M. Süer, and İ. Özkol, "Finite element modelling and analysis of simple lap joints," in Proceedings of 5th International Conference on Recent Advances in Space Technologies - RAST2011, 2011, pp. 68-72.

[37] M. Scheel et al., "Experimental assessment of polynomial nonlinear state-space and nonlinear-mode models for near-resonant vibrations," Mech. Syst. Signal Process., vol. 143, p. 106796, 2020. 